\title{
Aesthetic predicates: a hybrid dispositional
}

\section{account}

\author{
Teresa Marques
}

[Last Draft]

\begin{abstract}
This paper explores the possibility of developing a hybrid version of dispositional theories of aesthetic values. On such a theory, uses of aesthetic predicates express relational second-order dispositional properties. If the theory is not absolutist, it allows for the relativity of aesthetic values. But it may be objected to on the grounds that it fails to explain disagreement among subjects who are not disposed alike. This paper explores the possibility of adapting recent proposals of hybrid expressivist theories for moral predicates to the case of aesthetic predicates. Hybrid expressivist theories make no explicit commitment about the kind of property expressed by the predicate, but make explicit commitments to implicated (or presupposed) expressive content. It is argued that dispositionalism about the properties expressed by aesthetic predicates, combined with expressive implicatures (or presuppositions), can account for aesthetic disagreements even in cases where subjects are not relevantly alike.
\end{abstract}

KEYWORDS Aesthetic predicates; Dispositionalism; Hybrid expressivism; Presuppositions of commonality; Disagreement.

\section{Introduction}

This paper explores the possibility of developing a hybrid dispositional theory of aesthetic value. On such a theory, a use of an aesthetic predicate expresses a relational second-order dispositional property. The general virtues of a dispositional theory of value, such as Lewis (2000)'s account, are inherited by a dispositional theory of aesthetic value. Something has aesthetic value, on a dispositional theory, if it is something that we - the relevant class of individuals are disposed to value in ideal conditions of full imaginative acquaintance. The 
theory is cognitivist and allows for the communication of aesthetic truths. The theory is also naturalist, since aesthetic properties are dispositional second-order properties, and it is subjectivist, in some sense, since aesthetic properties are dependent on the appropriate responses of subjects of a given kind in certain conditions. Finally, the theory is also internalist about motivation.

If the theory is not universalist, i.e., if it does not require that absolutely everyone has the same responses under ideal conditions, then it allows for the relativization of aesthetic properties to different groups of individuals. It will however be objected to on the grounds that it fails to explain disagreement among subjects who do not have the same responses in the right conditions - those subjects would express different properties by their use of aesthetic predicates. ${ }^{1}$

A contextualist semantic theory can accommodate the relativization of aesthetic properties to the responses of different groups of individuals. A predicate like 'is beautiful', or 'is a good painting', uttered in context $C$, denotes a property such as beautiful for the perceivers relevant in context $C$ under the appreciation circumstances relevant in $C$, or simply beautiful for the standard relevant in $C$. The hypothesis seems especially fitting for a theory of aesthetic properties. It does not relativize aesthetic properties to individual subjects' responses, but to the responses of a collective group of individuals under (to specify) ideal conditions of full imaginative acquaintance. The theory leaves room for specialists in a given field to be better qualified to appreciate aesthetic value, and better positioned to recommend aesthetically valuable things.

Now, a hybrid expressivist theory allows moral claims to be assertions with truth-conditional content. Hybrid expressivism is hence a cognitivist theory. By making this allowance, it seems to dodge the Frege-Geach objection against simple expressivism. A hybrid expressivist theory keeps what is essential to expressivism: that moral claims express conative attitudes. This expressive component can be conveyed by means of a conventional implicature, ${ }^{2}$ a conversational implicature, ${ }^{3}$ or other secondary content. ${ }^{4}$ A hybrid expressivist theory places the evaluative component of moral discourse in the conative component expressed. This is a fundamental difference between hybrid expressivist theories and dispositional theories. A dispositional theory of value is a theory about the

\footnotetext{
${ }^{1}$ This is not the only objection to dispositionalism about values, as I point out below in the next section.

${ }^{2}$ Barker (2000), Copp (2001).

${ }^{3}$ Finlay (2005).

${ }^{4}$ Schroeder (2014).
} 
nature of value properties, the properties denoted by value terms.

Various authors have recently highlighted that speakers seem to have expectations of relevant similarity, or to make presuppositions of commonality, when engaged in discourse about value. ${ }^{5}$ This supplementation enriches the resources available to the contextualist to explain resilient impressions of disagreement. The assumption that speakers have expectations of relevant similarity, and that these are communicated pragmatically in discourse, effectively makes some contextualist and relativist accounts count as hybrid theories. Moreover, several authors on either side of the contextualism/relativism fence have appealed to the existence of an emotive or conative dimension associated to discourse and thought about matters of taste, of aesthetic and of moral value. ${ }^{6}$ Yet, it is not straightforward that presuppositions of commonality can help account for the resilient impressions of disagreement over aesthetic values presumed by various authors to be present. In fact, the idea that there is a presupposition of commonality has been challenged. ${ }^{7}$

This paper proposes a modification of the hybrid suggestion that is compatible with a Lewisian dispositional account of value. By doing so, the paper preserves the advantages of Lewis's theory, acquiring at the same time the advantages of a modified hybrid account. Even if two speakers do not express the same aesthetic property by their use of an aesthetic predicate, they convey pragmatically that they have a certain conative attitude, which may be in conflict with their interlocutors' attitudes. The paper offers an hypothesis about what is conveyed pragmatically and what that attitude is. The conveyed content is a presupposition that the speaker has a desire that the participants in the conversation (we) converge in their aesthetic dispositions. That desire is thus related to the expectations of similarity that are presumed by many authors to exist. On the resulting hybrid dispositionalist account sketched, what is genuinely evaluative is still the dispositional property denoted by the aesthetic predicate, unlike what happens in the case of hybrid expressivist accounts. ${ }^{8}$ The conveyed pragmatic content accounts for some resilient disagreement intuitions. Moreover, it does not succumb to Baker (2012)'s objections to presuppositional accounts. These are claimed to be advantages.

\footnotetext{
${ }^{5}$ For instance, López de Sa (2008), Egan (2012), Marques and García-Carpintero (2014).

${ }^{6}$ See López de Sa $(2008,2015)$, Sundell (2011), Huvenes (2012), Egan (2012, 2014), Stojanovic (2012), Marques and García-Carpintero (2014), Marques (2015).

${ }^{7}$ For instance by Baker (2012).

${ }^{8}$ In this respect, the sketched theory is closer to Strandberg (2012)'s dual aspect account of moral predicates.
} 
The next section adapts Lewis's dispositionalism about value for the aesthetic case, and criticizes Egan (2012)'s de se modification of dispositionalism. $\S 3$ criticizes Barker (2000)'s version of hybrid expressivism, and extracts consequences for other possible expressivist views. $\S 4$ offers the outline of the hybrid dispositional theory of aesthetic predicates.

\section{Dispositionalism about aesthetic properties}

There are good reasons to hold a relationalist ontological account of properties expressed by aesthetic predicates as secondary properties, for instance predicates such as 'is beautiful' or 'is good'. On this view, aesthetic predicates express relational dispositional properties relating the bearers of aesthetic properties to responses in subjects of certain kinds under certain circumstances (to aesthetic standards, for simplicity). Moreover, a single object can produce contrasting responses on different sensibilities, and presumably there is no good reason to take only one of them as veridical.

One such account is Lewis (2000)'s. On his account, a value property is something of the following kind:

$x$ is a value iff $x$ is disposed to elicit response $R$ in group of agents $G$ in circumstances $C$,

or, to the same effect,

$x$ is a value iff we are disposed to give response $R$ to $x$ in circumstances $C$.

For Lewis, the elicited response $R$ is a certain kind of motivational state, desiring to desire. We are the relevant group of agents $G$, and $C$ are conditions of full imaginative acquaintance. Lewis (2000) claims that his account has various advantages: it is cognitivist, naturalist, internalist about motivation, and subjectivist, because it is tied to facts about us. But it is not subjectivist in a solipsistic way - a value is not simply whatever a single individual desires at a given moment (Lewis, 2000, 68-69). One main issue that requires elaboration concerns us precisely, i.e., the relevant group of agents whose responses constitute values:

In making a judgment of value, one makes many claims at once, some stronger than others, some less confidently than others, and waits to see which can be made to stick. I say $X$ is a value; I mean that 
all mankind are disposed to value $X$; or anyway all nowadays are; or anyway all nowadays are except maybe some peculiar people on distant islands... or anyway you and I, talking here and now are; or anyway I am. How much am I claiming? - as much as I can get away with. . So long as I'm not challenged, there's no need to back down in advance; and there's no need to decide in advance how far I'd back down if pressed. What I mean to commit myself to is conditionally relative: relative if need be, but absolute otherwise (Lewis, 2000, 129).

To keep it simple, Lewisian dispositionalism in aesthetics assumes that an aesthetic predicate expresses an aesthetic property. So, 'beautiful' expresses the aesthetic property beauty. It is what beauty is that is a second-order dispositional property. If it is a universal property - i.e., if the dispositions at stake are elicited from everyone, or from everyone in normal (or ideal) conditions, then the semantics could be straightforwardly invariantist, under the condition that there is universal convergence in the relevant aesthetic responses. ${ }^{9}$

If our theory is conditionally relative, like Lewis's, then one option is for the theory to be contextualist: uttered in context $C$, ' $\mathrm{x}$ is valuable' expresses the proposition $x$ is valuable for the standard salient in $C$, or simply: $x$ is valuable for our standard in $C$, where "our standard" will vary (because who we are may vary). Conditionally relative dispositional accounts of aesthetic value allow for the variability in aesthetic standards across historical periods, cultures or traditions. ${ }^{10}$

Consider, for instance, the question of what is the highest value in painting.

\footnotetext{
${ }^{9}$ For a defense of such a view for aesthetic predicates, see Schafer (2011). He argues that predicates of taste denote non-instantiated absolute invariant properties. There is however plenty of evidence against uniformity in evaluations, as is testified by the history of art, anthropology, and psychology. The complex details of the metaphysics of the property are not part of the semantics. Nonetheless, there is an important sense in which the property denoted is semantically relevant: the property is what the predicate (e.g. 'beautiful') denotes. If there indeed is cross-cultural, or cross-personal, variability in the properties denoted, then the semantics should accommodate this fact. This is discussed in Marques and García-Carpintero (2014), where we address the question of how to understand a relationalist ontology. As we ask there, should we understand the theory as a descriptive or rather as a revisionary one? Cohen (2009) tentatively advances a descriptive interpretation for the color case. He correctly points out that the folk show some awareness of the main motivation for relationalism about colors. Following a familiar line on natural kind terms, it could be argued that relevant intuitions indicate that aesthetic predicates are intended to signify natural properties, and that it turns out that the natural properties providing the closest fit are variable relational ones.

${ }^{10} \mathrm{An}$ interesting recent study reports how music and emotion seem to be indissociable. In the study, Pygmies who had never listened to classical music were played several excerpts from Western pieces, and Westerners were played Pygmy music. Some songs typically trigger positive feelings from Westerners and others sad or negative emotions, but the same emotions were not triggered in Pygmies. This suggests, as the authors say, that the "subjective dimension of emotional valence might be mediated by cultural learning" (Egermann et al. (2015)).
} 
Imagine a discussion between two art critics, $A$ and $B$, about whether William Turner or the pre-Raphaelites are the better painters. On $A$ 's standard, truthfully capturing light and shadow in painting is the highest value. On $B$ 's standard, representing ideals of purity and authenticity unconstrained by classicist canons is the highest value. There does not seem to be any grounds on which to decide that one rather the other of these standards is more veridical. No doubt, one's response and capacity for appreciation of a painting can be trained and improved. Aesthetic taste can be educated. But we are assuming that these are fully trained art critics. On the assumption that they have different standards of aesthetic value, and on the assumption that a contextualist semantics for the aesthetic predicates adequately captures the response-dependence involved, we should account for a discussion between two art critics like Turner ${ }_{1}$ below:

Turner $_{1} \quad A$ : Turner is a better painter than the pre-Raphaelites.

$B$ : Turner is not a better painter than the pre-Raphaelites; the preRaphaelites are better.

People presumably feel that $A$ and $B$ disagree, but on contextualist accounts of the semantics of these sentences, the discussion above can be paraphrased thus:

Turner $_{2} \quad A$ : Turner is a better painter than the pre-Raphaelites, given A's standard.

B: Turner is not a better painter than the pre-Raphaelites, given B's standard.

There is, it is claimed, no impression of disagreement vis-à-vis Turner 2 . People are supposedly inclined to say that the contrast persists if we imagine that these two cases are not reports of a conversation, but rather reports of the thoughts of $A$ and $B$. In Turner ${ }_{1}, A$ and $B$ seem to disagree because, at least prima facie, it seems that they cannot be both right. By contrast, in Turner, ${ }_{2}$, both $A$ and $B$ can be right.

The non-convergence of aesthetic standards raises a risk, as Egan emphasizes,

[T] his fragmentation of the subject matter of different thinkers' and talkers' evaluative beliefs and assertions gives rise to a worry that the theory will not be able to explain the fact that difference in 
evaluative belief gives rise to (or just is) conflict and disagreement.

(Egan, 2012, 579). ${ }^{11}$

Egan proposes relativist dispositionalist theory of value. I will argue that his proposal also needs either a supplementation or a revision with respect to how it handles disagreement and conflict. Egan's account is motivated by the idea that difference in evaluative belief gives rise to (or just is) conflict and disagreement. ${ }^{12}$

On Egan's account, the existence of a common subject matter is guaranteed by the nature of the content of aesthetic statements. On his view, when the critic John Ruskin uttered 'Turner's Snow Storm: Steam-Boat off a Harbour's Mouth is a grand painting of sea-motion, mist and light', Ruskin self-ascribed a de se property, something like being disposed to value in way $w$ the representation of sea-motion, mist and light captured in Turner's painting Snow Storm: SteamBoat off a Harbour's Mouth. The main question that concerns us now is: does securing the same de se common subject matter guarantee that difference in belief just is conflict and disagreement? I will argue that it does not.

According to Egan, evaluative aesthetic terms express a de se dispositional property that is self-ascribed in belief (and in assertion). Also, he endorses a Stalnakerian account of assertion, where to assert is to put forward content that the audience can accept as part of the common ground. Since the content in these cases is just the dispositional de se property, to accept the property is to self-ascribe it. That gives us a straightforward account of communication about aesthetic value.

\footnotetext{
${ }^{11}$ Dispositional theories may be questioned on other grounds. The Lewisian theory claims to be internalist, naturalist, and cognitivist. But, as Egan also makes clear, authors like Blackburn (1984) or Gibbard (1990, 2003) have argued for non-cognitivism; authors like Parfit (2011), Wedgwood (2007), Enoch (2011) or Shafer-Landau (2003) have argued for non-naturalism; and some authors have discussed the plausibility of internalism, like Railton (1986), Svavarsdottir (1999), Dreier (2000). I am presupposing Lewis's dispositional theory, but do not intend to dismiss other objections that may be raised against the theory. I am anyway inclined towards a dispositional account. This paper is to be taken as defusing one possible objection to dispositional accounts.

${ }^{12}$ It is not the goal here to engage with other relativist views. There are several reasons for this. First, I sympathize with Egan's relativism more than others. Secondly, I don't engage here with MacFarlane's assessment-relativism, but I do so elsewhere. Both in other publications and in forthcoming work, I argue that assessment-relativism has serious pragmatic drawbacks, and lacks intuitive support. The theory has undesirable drawbacks with respect to the tensions it imposes on speakers' rationality. Elsewhere, I discuss mostly the appeal to intuitions about retractions. Recent experimental work by Knobe and Yalcin (2014), by myself (manuscript), and Kneer (2015), shows that relativist predictions for the semantics of epistemic modals are not supported by speakers' intuitions. I don't know of similar tests for aesthetic predicates. But the results for the modal cases, together with independent arguments, are indicative of broader problems for assessment-relativism.
} 
There are three levels of interpersonal incompatibility to be accounted for: disagreement in discourse, incompatibility in thought (doxastic attitude disagreement), and incompatibility or conflict in attitude (conflicting conative or non-doxastic attitudes). Egan offers an account of how disagreement in discourse takes place, consistent with Stalnaker's theory of assertion. He makes suggestions about incompatibility in thought and conflicts in attitude that, unfortunately, do not yield inter-personal incompatibility in thought or attitude. I focus mostly on the two later levels (attitude and thought) and will then assess how this impacts on the former (discourse).

The three levels of incompatibility are related. When is the self-ascription of a de se property true? A belief or an assertion that self-ascribes a de se dispositional property is true when the subject has the dispositional property in question. Now, if there is any incompatibility between self-ascribing a de se property desiring to desire $x$ and self-ascribing another de se property desiring not to desire $x$, presumably that resides in the underlying impossibility of the simultaneous truth of (i) and (ii) below:

(i) The subject desires to desire $x$;

(ii) The subject desires not to desire $x .^{13}$

This makes two crucial connections: first, it connects cognitive belief states (that self-ascribe a given dispositional property) with conative states (the dispositional property that is a desire to desire). Second, it connects the presumed impossibility of joint truth of (i) and (ii) with the subjective irrationality of selfascribing both de se properties. Now, if (i) and (ii) are incompatible, it must be because the conative attitudes that constitute those dispositional properties are themselves incompatible. Here, the conflict of the conative attitudes grounds the incompatibility of the cognitive attitudes.

Egan's proposal of how difference in evaluative belief gives rise to (or just is) conflict and disagreement makes the presumed subjective conative attitude incompatibility and the presumed subjective doxastic attitude incompatibility be the grounds for the interpersonal attitude incompatibility (doxastic and conative).

\footnotetext{
${ }^{13}$ Although the formulation "the subject does not desire to desire $x$ " is the proper wide scope negation of (i), this reading is compatible with a subject having no attitude at all towards desiring $x$. Presumably, given that we want to accommodate the cases where subjects have an attitude towards $x$, (ii) is the preferable reading: the subject self-ascribes a disposition not to value $x$.
} 
If I think $x$ is a value and you think it is not, you cannot come to believe what I believe without changing your mind. (Egan, 2012, 571)

The claim here is that no one can (rationally) self-ascribe a property and its negation, and hence that in cases like Turner ${ }_{1}$ there is, in a sense, a disagreement in thought between Ruskin and someone else who self-ascribed the negation of the relevant de se property.

Egan claims that the de se dispositionalist accounts for disagreement in discourse if we assume a Stalnakerian account of assertion. By asserting the sentence 'Turner's Snow Storm: Steam-Boat off a Harbour's Mouth is a grand painting ...' Ruskin is putting the sentence forward so that the audience selfascribes the relevant property. If anyone in the audience asserts the denial of this sentence, the speakers are putting forward incompatible ways to update the common ground.

When I assert "happiness is a value" and you assert "happiness is not a value," I am trying to add a property $F$ to the common ground, and you are trying to add its complement. We are trying to update the context in incompatible ways - trying to get our interlocutors to accept things that they cannot accept both of.(Egan, 2012, 574)

Together with the subjective rationality constraint above, the de se dispositional account would seem to offer the means to accommodate disagreement and incompatibility, as desired.

Question: does a subjective rationality constraint guarantee intersubjective incompatibility in thought? In other words, if one cannot rationally self-ascribe a pair of (apparently) incompatible properties - being disposed to value $x$ and being disposed to not value $x$-, then is it the case that if I self-ascribe one property and you self-ascribe the other, we have a doxastic disagreement? Given the connection between the belief that self-ascribes a dispositional value property, and the desire that constitutes the property, we would expect it to be the case that the interpersonal doxastic disagreement in de se dispositional belief is grounded on interpersonal attitudinal conflict.

I will reverse Egan's order of explanation to assess his proposal. I will start with attitudinal conflicts, then incompatibility in thought, and finally disagreement in discourse.

There are reasons to doubt that having different desires, in itself, raises a 
threat to one's rationality. ${ }^{14}$ We may, instead, argue that the only condition on the subjective rationality of desires rests on the possibility of satisfaction. The (im)possibility of satisfaction would provide a good basis on which to explain why it is not reasonable to self-ascribe a desire to $x$ and to self-ascribe a desire to not- $x$ - it is not reasonable if it is not possible for someone to satisfy both desires.

However, the fact that it is not possible for $A$ to satisfy both the desire to $x$ and the desire to not- $x$ does not entail that it is not possible for $A$ to satisfy a desire to $x$ and for $B$ to satisfy a desire to not- $x$. A may desire desiring being moved by Turner's painting, B may desire not desiring being moved by Turner's painting. But there is no intersubjective incompatibility in their desires.

Given the crucial connection between a de se desire and the self-ascription through belief of a de se desire, it should follow that there is no incompatibility in thought between two people if one self-ascribes a de se disposition to be moved by Turner and the other self-ascribes a de se disposition to not be moved by Turner.

However, even if there is a subjective incompatibility in a pair of desires (say, it would be unreasonable to desire $x$ and $y$ ) it does not thereby follow that when two different people desire each respectively $x$ and $y$, they are in conflict. It also does not follow that those people thereby disagree in thought. This example illustrates this:

Olives $A$ desires drinking martinis with green olives at a party. $B$ desires drinking martinis without any olives (since she hates olives). $A$ can have all the olives at the party, for all $B$ knows. There is no attitudinal conflict between $A$ and $B$. There is also no incompatibility in thought between $A$ 's selfascription of a desire to drink martinis with green olives, and $B$ 's selfascription of a desire to drink martinis with no olives.

On the other hand, having the same desires for the same things with the same properties can be a basis for conflict:

Heirs Two spoiled rich heirs fight over who's inheriting the family fortune: 'It's mine!', they claim. They desire the same, but are in conflict. And they also self-ascribe the same de se desire to inherit the family's fortune.

On the assumption that a dispositional theory of aesthetic value should account for conative attitudes about aesthetic value, we should not be satisfied by a $d e$

\footnotetext{
${ }^{14}$ Hume famously argued against the idea that it can be 'unreasonable' to have different 'affections' or 'passions', and claimed that they could only be unreasonable if their objects didn't exist or the means to satisfy them were insufficient. (Hume, 1978, T2, 3, 3).
} 
se, relativist, dispositional account of aesthetic values, since it clearly fails to account for the conflict of those attitudes. It fails, in particular, to accommodate interpersonal conflict of desires when these are de se. The theory also fails to accommodate interpersonal incompatibility in de se thought. The subjective rationality constraint is an irrelevant consideration when the question of interpersonal incompatibility in thought arises.

We may now suspect that the appeal to Stalnaker's account of assertion to explain communication about aesthetic properties is unmotivated, given the limitations of the de se theory to account for incompatibility in thought. ${ }^{15}$

The appeal to a Stalnakerian account of assertion is unmotivated because, absent any automatic interpersonal incompatibility in thought when diverse de se properties are self-ascribed by different people, there is no clear reason to accept that what one does when one communicates about aesthetic values is to get others to self-ascribe a de se property that one also self-ascribes. A contextualist dispositional theory at least has the advantage of predicting that sets of similarly constituted people have certain shared dispositions to respond to the relevant aesthetic objects in ideal conditions of imaginative acquaintance. How is this preferable?

The Lewisian theory has a parsimonious way to account for an aesthetic disagreement when the subjects in disagreement are relevantly alike. If "under less-than-ideal conditions we may wrongly value what is not really good' (Lewis, 2000,71 ), then we can disagree (in thought) about what is good. What I think is a value may not be what you think is a value. If we are all relevantly alike, then there is a straightforward disagreement in thought (and one of us is wrong). Any given object will have, or lack, the relevant response-dependent property, and each of us is either right or wrong in ascribing that property to that object.

This opens up the possibility of attitudinal conflict, for which Lewis provided the blueprint. On a dispositional account of aesthetic value, if it is true that one has the relevant disposition, then one has a certain (second-order) desire. This desire can be satisfied or fail to be satisfied. Lewis drew the distinction between

\footnotetext{
${ }^{15}$ Egan limits the range of de se contents that can be expressed in discourse. The most obvious candidates - various forms of indexical and self-locating discourse - don't express de se contents, he claims, because that would have unintuitive consequences on a straightforward Stalnakerian account of assertion. That's a controversial move. For alternative accounts, see Torre (2010) or Ninan (2013). Egan has to say something about why evaluative discourse is distinct from other cases. He claims that the difference concerns expectations of attitudinal convergence which don't exist in those other cases. But the examples given, Olives and Heirs, indicate that convergence of de se desires is neither a sufficient nor a necessary condition for harmony and compatibility of attitudes (whether doxastic or conative).
} 
agreeing or disagreeing in desires and desiring alike. Two people (dis)agree in desires when the same world can(not) satisfy the desires of both. They desire alike when they are 'psychological duplicates', and have exactly the same desires. Whether or not the same world can satisfy two people is different from whether or not they desire alike (i.e., whether they have the same desires). The examples discussed previously (Olives and Heirs) illustrate this and the fact that desiring alike is not equivalent to agreeing in desire.

Suppose now that this is true for all of us: we desire to desire $x$ (in the right conditions). Yet, some of us do not desire $x$, those of us who are like the thoughtful addict who does not value what he desires. We may also assume that some of us that do not desire $x$ are mistakenly convinced that we do not desire to desire $x$. Moreover, if some of us do desire $x$ in the right conditions, and some of us do not desire $x$ in those conditions, then our shared desire to desire $x$ is not jointly satisfied.

However, in a dispute like Turner ${ }_{1}$ in ideal conditions of full imaginative acquaintance, $A$ and $B$ are not relevantly alike. The conditional relativization of the dispositional theory allows for the possibility that both $A$ and $B$ speak truly. Disagreements in thought may be more or less contained, circumscribed to sets of similarly disposed people. In these cases, there will be disagreement in thought within groups of people that share a culture, a tradition, who are relevantly constituted alike, etc. Within those sets of people, there will be disagreement in thought in the same way as there is in the case where the dispositional property includes everyone. However, in limiting cases, there won't be any disagreements in thought, either because there is cross-cultural variation in value properties, or because value properties are first-person singular. Either way, a conditionally relative theory has a prima facie advantage over a purely de se theory: the de se account covers no case of disagreement in thought about value.

What is missing from either theory is an account of the resilient conflict (if any) that remains among people who are not similarly constituted (or similarly educated) with respect to aesthetic value. It is an open question whether that resilient conflict is about values. The next session explores the prospects of a version of hybrid pluralist semantics for aesthetic predicates. 


\section{Hybrid expressivism for aesthetic predicates?}

Expressivism about evaluative (moral) sentences holds that these sentences are conventional ways of expressing certain kinds of attitudes. Simple naïve expressivism makes sentences like 'lying is bad' express attitudes akin to those expressed by 'Boo lying!', and is seen as interpreting 'lying is bad' as an expression of a speaker's disapproval of lying, and nothing else. A problem for naïve expressivism is the so-called Frege-Geach problem. ${ }^{16}$

A recent modification, hybrid expressivism, has been defended in different ways by various authors. ${ }^{17}$ Hybrid expressivism is a strategy to evade the Frege-Geach objection, preserving some form of cognitivism, while at the same time keeping what is essential to expressivism: that moral statements express conative attitudes:

An evaluative predicate, like 'good'/'bad', expresses a property that compositionally contributes to the truth-conditions of the sentences where it occurs.

Speakers express a conative attitude towards that property.

Different authors have appealed to diverse pragmatic mechanisms to account for the expression of a conative attitude in evaluative discourse. Some authors like Barker (2000) and Copp (2001) appeal to conventional but non-truth conditional aspects of meaning, e.g., conventional implicatures, to convey how the expressive motivational component of moral discourse is communicated.

Other authors point out that the claim that these implicatures are conventional faces serious objections. For instance, Schroeder (2009) and Strandberg (2012) argue that there are several arguments against the claim that expressive content is communicated through conventional implicatures. The idea that sentences with value predicates conventionally implicate that the speaker has a certain conative attitude imports to the case of value predicates similar claims that have been made about pejoratives. ${ }^{18}$ But there are important disanalogies between uses of values terms and uses of pejorative terms. In the latter case, a pejorative attitude is expressed even when the sentence with a pejorative term appears embedded in a more complex sentence. However, when value terms occur in embedded sentences, no attitude is standardly expressed.

\footnotetext{
${ }^{16}$ For a summary, see Schroeder (2008).

${ }^{17}$ For instance Barker (2000), Copp (2001), Finlay (2005), Ridge (2006), and Schroeder (2009).

${ }^{18}$ See Hom (2010) for an overview about pejoratives.
} 
In response, some have argued that attitudinal content is pragmatically communicated but is not conventional, as Finlay (2005) and Strandberg (2012) do. Strandberg, for instance, argues that expressive content is communicated through generalized conversational implicatures. Although Strandberg is not an expressivist, a common aspect between Strandberg and other theorists is that the further non-truth-conditional content communicated is that the speaker has a certain attitude towards $\phi$ ing.

The point of discussing hybrid expressivism here is to draw inspiration from approaches that allow for semantic pluralism in order to account for diverse aspects of communication and discourse in a given domain, and to critically avoid some explanatory pitfalls. In the case that concerns us presently, the goal is to explain the expression of conflict in discourse in cases where speakers are not relevantly alike.

For illustration purposes, and for its simplicity, I discuss here Barker (2000)'s version of hybrid expressivism. He applies the distinction between asserted and implicated content to value sentences. On Barker's Implicature Theory (IT):

IT If $U$ asserts the sentence ' $\mathrm{T}$ is good', then $U$ denotes a property $F$ by 'good' and:

(i) $U$ expresses-as-explicature the content that $T$ is $F$ [i.e., $U$ asserts];

(ii) $U$ expresses-as-implicature the content that $U$ is committed to approval of $F$-things [i.e., $U$ implicates].

(iii) $U$ conveys that she believes the contents in (i) and (ii);

(iv) $U$ conveys that she approves of $T$. (Barker, 2000, 271)

On this view, the asserted content of a value sentence is truth-conditional content - that $T$ is $F$. F itself is a natural property, and may vary from context to context: the property is fixed as that towards which a speaker has a pro (or con) attitude. ${ }^{19}$

The meaning of evaluative predicates like 'good' is such that:

F: 'good' - as uttered by $U-\operatorname{denotes} F$ such that:

(a) $U$ is committed to moral approval of $F$-things.

(b) This $F$-attitude is shared by or uncontroversial for audience. (Barker, 2000, 277)

\footnotetext{
${ }^{19}$ Other authors have argued that $F$ could be a constant property (Copp 2001). That avoids some, but not all, of the objections I raise below.
} 
$F(a)$ is part of the semantics of 'good', it's its character. Whereas $F(b)$ is a pragmatic implicature (Barker, 2000, 277). Also, $F$-attitudes are marked as shared or uncontroversial, ${ }^{20}$ i.e., $F(a)$ and $F(b)$ are implicatures marked as part of the common-ground. Finally, on his theory, the $F$-property is not a value. A simple modification of hybrid moral expressivism provides a similar theory for aesthetic predicates. The only difference resides in the kind of approval attitude involved in the moral and in the aesthetic case.

Can the implicature F(a) convey the evaluative component of aesthetic/moral value judgments? As noticed earlier, one problem with $\mathrm{F}$ (a) being conventional is that when value terms occur in embedded sentences, no attitude is standardly expressed. This raises doubts as to whether $\mathrm{F}(\mathrm{a})$ is a conventional implicature. In any case, whether $\mathrm{F}(\mathrm{a})$ is conventional or not, it is central to expressivism that a value statement expresses a speaker's pro-attitude.

When people refer to attitudes in the context of expressivism, they often mean first-order first-personal conative attitudes (e.g. my occurring desire for drinking coffee). On Barker's account, the implicature $F(a)$ is that the speaker approves of an $F$ property. The question is: where lies the value in one's approval/desire of $x$ ? As Lewis argues,

... we better not say valuing something is just the same as desiring it. That may do for some of us: those who manage, by strength of will or good luck, to desire exactly as they desire to desire. But not all of us are so fortunate. The thoughtful addict may desire his euphoric state but does not value it... He does not desire his unaltered, mundane state of consciousness, but he does desire to desire it. We conclude that he does not value what he desires, but rather he values what he desires to desire. (Lewis, 2000, 70-71)

This argument provides a good reason against simple first-order attitudes constituting value. It is not enough that one approves of $F$ for $F$ to be valuable. Conflicts and disagreements create further problems, at least for Barker's version of expressivism.

For Barker, 'good' has a character that determines in context the property $F$ that the speaker approves. Let us assume that there is a conversational implicature that the $F$ attitude is shared by audience/interpreter, i.e., that speaker and audience are both committed to the approval of $F$ things. If it is not the case that speaker and audience both are committed to the approval of $F$

\footnotetext{
${ }^{20}$ See (Barker, 2000, 272).
} 
things, what follows? First, that the properties approved by the speaker and by the audience are not the same. This rules out the possibility of straightforward disagreement in assertion.

The question now is: is there any metalinguistic disagreement between speaker and audience when it is clear that speaker and audience do not approve the same properties? Barker explains metalinguistic disagreement thus:

Disagreement can also be expressed through negation. As ' $T$ is good' has both explicature and implicature, it has two forms of negation: explicature based, i.e. truth-conditional negation, and implicaturebased, i.e. metalinguistic negation. In reply to someone's assertion that Jane is good, $U$ might assert:

(17) Jane is not good. She is often heartlessly cruel.

(18) Jane is not good. Being good does not reside in brutal honesty at all costs.

(17) involves truth-conditional negation: the explicature that she is never heartlessly cruel, which is part of the $F$-property intended by the speaker, is the focus of negation. In (18) the negation is metalinguistic; the focus of negation is the implicature that a certain $F$-attitude is shared by speaker and audience: approval of brutal honesty at all costs.(Barker, 2000, 278)

A comparison with a different case helps understand what is at issue here. In the film The Pink Panther Strikes Again, inspector Clouseau has an exchange with a concierge. He asks: "Does your dog bite?", pointing to a dog in the hotel lobby. The concierge replies, "No [my dog does not bite]." Clouseau pets the dog in the lobby and is bitten. Upset, he confronts the concierge: "I thought you said your dog not bite." The concierge replies, "That is not my dog."

In the dialogue, Clouseau's use of 'your dog' refers to the dog in the lobby, and he presupposes that the concierge refers to the same dog. That presupposition fails, as the concierge makes clear. It is clear that there is a misunderstanding in that conversation due to an equivocation about the reference of that token of 'your dog'. Now, does this dialogue convey a disagreement about the referent of 'your dog'? I don't see that it does.

The dialogue would express a disagreement if Clouseau insisted that the dog in question is indeed the concierge's and that his use of 'your dog' and the concierge's referred to the same dog. The metalinguistic disagreement would be about whether there was a shared reference in the dialogue. The disagreement 
would not be about the dog and its dispositions to bite, but about what their utterances referred.

So, what is denied in the denial of the implicature $\mathrm{F}(\mathrm{b})$ ? What is denied, given Barker's theory, is that the speaker and the audience both approve of the same thing. If this amounts to a disagreement, it is a disagreement about whether the participants of the conversation share the same dispositions. It is not a disagreement about the aesthetic (or moral) value of $x$ (contrast above). A metalinguistic disagreement here would be a disagreement between a speaker and an audience, whereby the speaker defends the claim we approve/desire the same things and the audience defends the claim we do not approve/desire the same things. This is unfortunate. It means that the only disagreement left between people who do not approve of the same things is not a moral disagreement, but a disagreement about themselves - the participants in the conversation.

Moreover, this is of no help in Turner ${ }_{1} . \mathrm{F}(\mathrm{b})$ is meant to be a conversational implicature. That means that in certain kinds of contexts that clearly defeat the implicature it does not arise. Turner ${ }_{1}$ is one such context. Recall that we were assuming that $A$ and $B$ are fully trained art critics. Not only do they have different standards of aesthetic value, they are also aware that they do not share the same aesthetic standard. It is common knowledge that they do not share standards. There is here no chance of a misunderstanding as to what standards each fully trained art critic endorses. But $A$ and $B$ are nonetheless in conflict.

Since this is a real possibility, it means that a theory with the features of Barker (2000)'s fails to explain disagreement at various possible levels: $A$ and $B$ do not disagree in discourse (they do not denote the same property because they do not aesthetically approve of the same things). They do not disagree in thought, for the same reason. They do not have conflicting attitudes, because approving different things does not, in itself, amount to being in conflict. They do not even have a metalinguistic disagreement about some putative shared aesthetic standard, because they are perfectly aware that they don't approve of the same properties in works of art. Furthermore, it is dubious whether and how approving of something in itself confers value to what is approved.

If a dispositional theory is to take a page from hybrid expressivism, it must find a way to accommodate pragmatic expressions of conflicting attitudes in conversation to explain remaining impressions of disagreement among people that are not disposed alike. But it must revise what the conveyed content is. ${ }^{21}$

\footnotetext{
${ }^{21}$ Arguably, more complex forms of hybrid expressivism than the one discussed here have further resources to approach the problem. For a comprehensive overview, see Schroeder
} 


\section{Hybrid dispositionalism}

Can a hybrid dispositional theory explain what is evaluative about evaluative thought and discourse, and have enough resources to explain even resilient impressions of disagreement? This section tries to motivate and outline hybrid dispositionalism.

One can, presumably, adapt hybrid expressivism so that the property denoted by a value predicate is dispositional. ${ }^{22}$ The aesthetic property could be a Lewisian dispositional property, and the resulting semantics would be contextualist. Alternatively, the dispositional property could be a de se property, and the resulting semantics would be relativist. In either case, there are good reasons to assume that further content is conveyed in conversation, and that that content can give rise to conflict.

As Egan suggests, "[o]ne very major role that aesthetic discourse plays is a sort of connection-building role, in which people discover commonalities in the sorts of things that they enjoy, appreciate, or despise". Let us assume that it is true that establishing commonalities is a "substantial part of the process of building and maintaining interpersonal relationships" (Egan, 2010, 260). ${ }^{23}$

The hybridization of the dispositional theory consists in spelling out the nature and the content of the non-truth conditional content conveyed in discourse. This should allow us to explain how conversations like Turner ${ }_{1}$ express incompatibility. In previous work, I assumed that the content conveyed is a presupposition of commonality, in line with the work of other authors (for instance, López de Sa (2008)). This differed from the content that expressivists assume is conveyed through implicature: that the speaker has a certain conative attitude. I believe that we communicate the two kinds of contents: that the speaker has a certain attitude, and an expectation of commonality. Yet, the idea that aesthetic predicates express a presupposition of commonality has been challenged by Baker (2012), with three tests of presuppositionality. The tests are the "Hey, wait a minute!" test, the "... and what's more" test, and the infelicitous cancellation test. Here I will only focus on the first and that last.

The Hey, wait a minute! test for presuppositions is described by von Fintel (2004) and by Yablo (2006):

(2009), and for recent contributions on the topic, see Fletcher and Ridge (2014).

${ }^{22}$ Strandberg (2012) also claims that value terms express value properties (although not dispositional ones), and that emotive content is expressed through a conversational implicature.

${ }^{23}$ Marques (2015) reviews research in psychology and cognitive science that supports this claim for a subclass of attitudes. 
[i]f $\pi$ is presupposed by $S$, then it makes sense for an audience previously unaware of $\pi$ to respond to an utterance of $S$ by saying "Hey, wait a minute, I didn't know that $\pi$. (Yablo, 2006, 165)

Baker gives the following example:

1. A: The mathematician who proved Goldbach's Conjecture is a woman.

$B$ : Hey, wait a minute. I had no idea that someone proved Goldbach's conjecture.

The test shows that $A$ 's utterance seems to carry the presupposition that someone has proved Goldbach's conjecture. As Potts (2013) says, presuppositions are contents that speakers take for granted and assume to be uncontroversial. This makes objecting to presuppositions difficult, because it requires a disruption of the normal flow of discourse to bring back the presupposed item for discussion, as $B$ does above. If there was a presupposition of commonality in attributions of beauty, Baker argues, then we should have the same result in this sort of case:

2. A: Dubrovnik is beautiful.

$B$ : Hey, wait a minute. I had no idea that we were alike with respect to beauty judgments.

But, Baker claims, $B$ 's response here would be odd, and it would be natural for $A$ to reply that she had never suggested that they were alike with respect to beauty judgments (as $A$ would contend in a case like Turner 1 ). ${ }^{24}$ Finally, Baker argues that presuppositions of commonality also fail the infelicitous cancellation test. The test is roughly as follows: "If I assert $S$ and presuppose $\pi$, then an immediate denial of $\pi$ makes my collective utterance puzzling." (Baker, 2012, 119) Here is an example:

3. John has stopped leaving towels on the floor, although he never left towels on the floor.

4. ( $A$ to $B$ :) Dubrovnik is beautiful, although we are not alike with respect to beauty-judgments.

Whereas (3) is infelicitous, (4) is not, which suggests that "Dubrovnik is beautiful" does not express the presumed presupposition. ${ }^{25}$

\footnotetext{
${ }^{24}$ The "... and what's more ..." test is also put forward by Yablo (2006) and von Fintel (2004). I will skip discussion of this test, for present concerns. (Baker, 2012, 118).

${ }^{25}$ In Marques and García-Carpintero (2014), we criticize Baker by drawing attention to other cases where contextualist semantics is adequate, but where the three suggested tests would suggest that these presuppositions of commonality are not present.
} 
Either way, a putative presupposition that interlocutors are relevantly similar is false in dialogues like Turner ${ }_{1}$, which means that the false presupposition cannot even explain a metalinguistic disagreement in that case (see above).

Now, let us assume, with Egan, that aesthetic discourse serves to communicate beliefs about the aesthetic value of certain objects, and that aesthetic discourse plays "a sort of connection-building role" (Egan, 2010, 260). This requires that aesthetic discourse serves to communicate: (a) beliefs about aesthetic value and (b) what the speaker enjoys, appreciates or despises things with relevant aesthetic value. Finally, it requires, (c), that aesthetic discourse has a "connection-building role". From the discussion in the previous sections, we can rule out that the content of the belief communicated is that the speaker enjoys, appreciates or despises $x$, and can rule out that the content is that speaker and audience are relevantly alike in what they appreciate or enjoy.

The positive thesis this paper makes is that (b) and (c) are achieved through pragmatic means. Those pragmatic means can be either presuppositions, or generalized conversational implicatures. A difference between a presupposition and an implicature seems to be that a presupposition is assumed to be uncontroversial and part of the common ground:

If A presupposes B, then A not only implies B but also implies that the truth of B is somehow taken for granted, treated as uncontroversial. (Chierchia and McConnell-Ginet, 2000, 28).

In contrast, a conversational implicature is an inference that is required to be made on the assumption that the speaker is rational, is being cooperative, is following Gricean conversational maxims, etc.

The "Hey, wait a minute!" test is arguably a necessary condition for presuppositionality. But the same test can be used to object to other not-at-issue content. ${ }^{26}$ Given the complexity of the debate, I do not purport to decide here whether the pragmatic content at stake is a presupposition or a conversational implicature.

In support of the view that they are conversational implicatures, it appears that we can modify Strandberg (2012)'s calculation of a conversational implicature in the moral case for our present purposes. Let us assume that a critic is rational, cooperative, and follows the maxim of relation: make your contribution so as to be relevant in order to fulfill the purposes of the conversation.

\footnotetext{
${ }^{26}$ See Potts $(2013,2008)$, and Tonhauser et al. (2013) on a taxonomy of projective not-atissue content.
} 
On a dispositional theory, in order to understand the critic who says that a painting is beautiful, we must take her to ascribe to a painting the disposition to cause in observers (we) a desire to have certain aesthetic responses to it. To understand the critic as making a relevant contribution to the aesthetic conversation, we ought to understand her as desiring that we (the people sharing her aesthetic standard) have those aesthetic responses to that painting. Thus, her utterance conversationally implicates that she desires that the people who share her standard have a certain response to the painting. Since she is one of those people, she is implicating that she herself desires to have the relevant aesthetic responses to the painting -that she values it. Since desires are motivating, and we are assuming that she is rational, we can also infer that she strives to satisfy her desire to have the relevant responses to the painting. So, we can calculate (b) - by saying that Turner's painting is beautiful, or is a great painting, $A$ communicates that she has the right aesthetic response towards it.

Can we calculate (c), an implicature that serves a "connection building role"? Again, let us assume that a critic is cooperative and rational, and follows the conversational maxims, namely relation. The critic may find herself in conversations like Turner ${ }_{1}$, where she is aware that her interlocutor does not share her aesthetic standards, i.e., does not desire to have aesthetic response $w$ to Turner's painting, but rather desires to have response $u$. A says that Turner's is a great painting, thereby saying that we (the set of people that share her standard) are disposed to aesthetically appreciate it. She cannot be conveying that her interlocutor is a member of the group referred to with 'we', since she knows that she and her interlocutor know that is false. But, given that it is common knowledge that there is no shared standard, the connection building purpose of aesthetic discourse, $A$ 's insistence in making the assertion, and that we have no reason to believe that she does not conform to the maxim of relation, we can infer that she desires that she and her interlocutor come to share the same aesthetic standard.

Both versions of dispositionalism about aesthetic value can be hybridized to capture both implicatures. We start by a Lewisian theory, where a value is what we desire to desire under ideal conditions of full imaginative acquaintance. The hybrid dispositional $\left(H D_{C}\right)$ would say:

$H D_{C}$ If $U$ asserts the sentence ' $\mathrm{x}$ is good', then $U$ expresses a dispositional property we desire to desire $x$ in way $w$ in ideal conditions by 'good' and asserts that $x$ has that property (where 'we' refers to the group of relevantly similar people). 
(i) In asserting ' $\mathrm{x}$ is good', $U$ conveys that she desires $x$ (in way $w$ );

(ii) $U$ conveys that she desires that we desire to desire $x$ (where 'we' refers to the participants in the conversation).

In this hybrid version of dispositionalism, (i) and (ii) are implicatures that express the speaker's desires. Further reasons to treat (i) and (ii) as conversational implicatures is that they seem to be cancelable (this would normally count against seeing (i) and (ii) as presuppositions). For example, there is no contradiction for $A$ in saying:

5. $(A:) x$ is a good painting, but I don't like it.

It is equally not contradictory for $A$ to say:

6. $(A:) x$ is a good painting, but I don't expect you to value it (or, I don't expect you to like it).

However, there are purely pragmatic presuppositions, i.e., presuppositions not triggered as part of the semantic meaning of some lexical item or expression. In fact Stalnaker argues for this view for many presuppositions, ${ }^{27}$ and writers such as Simons argue that it applies to all. ${ }^{28}$ Moreover, (i) seems to satisfy the "Hey wait a minute!" test, which is a necessary but not a sufficient condition of presuppositionality.

Consider for instance this interchange:

7. (A:) $x$ is a good painting.

8. ( $B$ :) Hey, wait a minute! I didn't know you were into this kind of art.

It would seem that (ii) also satisfies the test:

9. $(A:) x$ is a good painting.

10. ( $B$ :) Hey, wait a minute! You can't expect us to find this valuable.

In a hybrid contextualist dispositional theory like the one sketched, the extension of 'we' that determines the aesthetic value property expressed is not the speaker and his audience. Rather, 'we' refers to the class of people that are constituted or disposed like the speaker in the relevant respects.

This means that in that conversation, speaker and audience don't really disagree doxastically. But they can have a conflict of attitudes if the speaker

\footnotetext{
${ }^{27}$ Stalnaker $(1973,1974,1998,1999)$.

${ }^{28}$ Simons (2003, 2005, 2006), for instance.
} 
implicates that she desires that the conversational participants share her standards, and if it becomes clear that this desire will not be satisfied. A hybrid theory of this kind can explain why they have a conflict of attitudes, even if $A$ and $B$ both speak truly in the conversation, and are aware that they do not share aesthetic standards. This is some progress with respect to other theories that aim to defend semantic contextualism. Other accounts of this sort, like Sundell (2011) or Huvenes (2012), do not explain where the conflict of attitudes comes from or how it arises.

The second dispositional theory is relativist and treats the expressed dispositional property as a self-ascribable de se property. As argued in $\S 2$, the de se dispositional theory does not seem able to explain why central cases like Turner $_{1}$ express aesthetic disagreement in thought. Yet, a hybrid relativist dispositional theory can accommodate attitudinal conflicts. On this second version of dispositionalism about aesthetic values $\left(H D_{R}\right)$ :

$H D_{R}$ If $U$ asserts the sentence ' $\mathrm{x}$ is good', then $U$ self-ascribes a de se dispositional property desiring to desire $x$ in way $w$ in ideal conditions by 'good' and:

(i) $U$ conveys that she desires $x$ in way $w$;

(ii) $U$ conveys that she desires that we desire to desire $x$ in way $w$.

This allows the expression of a desire that can fail to be satisfied, and hence gives rise to attitudinal conflicts between speaker and audience. If the speaker desires that the participants in the conversation value $x$, but the audience does not, speaker and audience have desires that cannot be jointly satisfied. There is a conflict of attitudes that is expressed in discourse, even when speaker and audience do not share aesthetic standards.

Although the differences between the contextualist and the relativist hybrid dispositional theories do not conclusively weigh in favor of one or the other version, the clarification of the nature of the presupposed content gives readers the resources to better decide between the two accounts. For instance, the contextual dispositionalist theory casts a wider net than the de se relativist theory: the class of people who are relevantly like the speaker, and that partly determine what a given aesthetic standard is, may be very large. If my criticism of dispositional relativism is right, then it fails to capture disagreement in thought, since the subjective rationality constraint on the self-ascription of incompatible properties does not ground intersubjective disagreements. However, supplementing either version of dispositionalism with an expressive conversational implicature 
(or presupposition) allows for the expression of conflicting conative attitudes. This affords hybrid dispositionalist theories resources to accommodate conflicts that other theories lacked.

\section{References}

Baker, C. (2012). Indexical contextualism and the challenges from disagreement. Philosophical Studies 157(1), 107-123.

Barker, S. J. (2000). Is value content a component of conventional implicature? Analysis 60 (267), 268-279.

Blackburn, S. (1984). Spreading the Word. Oxford: Clarendon Press.

Chierchia, G. and S. McConnell-Ginet (2000). Meaning and Grammar: An Introduction to Semantics. MIT Press.

Cohen, J. (2009). The Red and The Real. Oxford: Oxford University Press.

Copp, D. (2001). Realist-expressivism: A neglected option for moral realism. Social Philosophy and Policy 18(02), 1-43.

Dreier, J. (2000). Dispositions and Fetishes: Externalist Models of Moral Motivation. Philosophy and Phenomenological Research 61(3), 619-638.

Egan, A. (2010). Disputing about taste. In T. Warfield and R. Feldman (Eds.), Disagreement, pp. 247-286. OUP.

Egan, A. (2012). Relativist dispositional theories of value. Southern Journal of Philosophy 50(4), 557-582.

Egan, A. (2014). There's something funny about comedy: A case study in faultless disagreement. Erkenntnis $79(1), 73-100$.

Egermann, H., N. Fernando, L. Chuen, and S. McAdams (2015). Music induces universal emotion-related psychophysiological responses: Comparing Canadian listeners to Congolese Pygmies. Frontiers in Psychology 5(1341), 1 - 9.

Enoch, D. (2011). Taking Morality Seriously: A Defense of Robust Realism. Oxford University Press.

Finlay, S. (2005). Value and implicature. Philosophers' Imprint 5(4), 1-20.

Fletcher, G. and M. Ridge (2014). Having it Both Ways: Hybrid Theories and Modern Metaethics. Oxford: Oxford University Press.

Gibbard, A. (1990). Wise Choices, Apt Feelings: A Theory of Normative Judgment. Harvard University Press.

Gibbard, A. (2003). Thinking How to Live. Harvard University Press.

Hom, C. (2010). Pejoratives. Philosophy Compass 5(2), 164-185. 
Hume, D. (1978). A Treatise of Human Nature (ed. L. A. Selby-Bigge, rev. P. H. Nidditch ed.). Oxford: Clarendon Press.

Huvenes, T. T. (2012). Varieties of disagreement and predicates of taste. Australasian Journal of Philosophy 90(1), 167-181.

Kneer, M. (2015). Truth-assessment and retraction of epistemic modals: Empirical data. Manuscript.

Knobe, J. and S. Yalcin (2014). Epistemic modals and context: Experimental data. Semantics and Pragmatics 7(10), 1-21.

Lewis, D. (1989/2000). Dispositional theories of value. Proceedings of the Aristotelian Society 63, 113-137. (Reprinted in Papers in Ethics and Social Philosophy, Cambridge: Cambridge University Press, 2000 (q.v.)).

López de Sa, D. (2008). Presuppositions of commonality: An indexical relativist account of disagreement. In M. García-Carpintero and M. Kölbel (Eds.), Relative Truth, pp. 297-310. Oxford: Oxford University Press.

López de Sa, D. (2015). Expressing disagreement: A presuppositional indexical contextualist relativist account. Erkenntnis 80(1), 153-165.

Marques, T. (2015). Disagreeing in context. Frontiers in Psychology 6(257), 1-12.

Marques, T. and M. García-Carpintero (2014). Disagreement about taste: Commonality presuppositions and coordination. Australasian Journal of Philosophy 92(4), 701-723.

Ninan, D. (2013). Selflocation and otherlocation. Philosophy and Phenomenological Research 87(1), 301-331.

Parfit, D. (2011). On What Matters. Oxford University Press.

Potts, C. (2008). Wait a minute! What kind of discourse strategy is this? Annotated data. Online at http://christopherpotts.net/ling/data/waitaminute/.

Potts, C. (2013). Presupposition and implicature. In S. Lappin and C. Fox (Eds.), The Handbook of Contemporary Semantic Theory (2nd ed.). Wiley-Blackwell.

Railton, P. (1986). Moral Realism. Philosophical Review 95(2), 163-207.

Ridge, M. (2006). Ecumenical expressivism: Finessing Frege. Ethics 116(2), 302-336.

Schafer, K. (2011). Faultless disagreement and aesthetic realism. Philosophy and Phenomenological Research 82(2), 265-286.

Schroeder, M. (2008). What is the Frege-Geach problem? Philosophy Compass 3(4), 703-720.

Schroeder, M. (2009). Hybrid expressivism: Virtues and vices. Ethics 119(2), 257-309.

Schroeder, M. (2014). Truth in hybrid semantics. In G. Fletcher and M. Ridge (Eds.), Having it Both Ways: Hybrid Theories and Modern Metaethics. Oxford. 
Shafer-Landau, R. (2003). Moral Realism: A Defence. Oxford University Press.

Simons, M. (2003). Presupposition and Accommodation: Understanding the Stalnakerian Picture. Philosophical Studies 112(3), 251-278.

Simons, M. (2005). Presuppositions and Relevance. In Zoltán Gendler Szabó (Ed.), Semantics Versus Pragmatics, pp. 329-255. Oxford University Press.

Simons, M. (2006). Foundational Issues in Presupposition. Philosophy Compass 1(4), $357-372$.

Stalnaker, R. (1973). Presuppositions. Journal of Philosophical Logic 2(4), 447-457.

Stalnaker, R. (1974). Pragmatic Presuppositions. In Robert Stalnaker (Ed.), Context and Content, pp. 47-62. Oxford University Press.

Stalnaker, R. (1998). On the Representation of Context. Journal of Logic, Language and Information 7(1), 3-19.

Stalnaker, R. (1999). Context and Content: Essays on Intentionality in Speech and Thought. Oxford University Press.

Stojanovic, I. (2012). Emotional disagreement: The role of semantic content in the expression of, and disagreement over, emotional values. Dialogue 51(1), 99-117.

Strandberg, C. (2012). A Dual Aspect Account of Moral Language. Philosophy and Phenomenological Research 84(1), 87-122.

Sundell, T. (2011). Disagreements about taste. Philosophical Studies 155(2), 267-288.

Svavarsdottir, S. (1999). Moral Cognitivism and Motivation. Philosophical Review 108(2), 161-219.

Tonhauser, J., D. I. Beaver, C. Roberts, and M. Simons (2013). Towards a taxonomy of projective content. Language 89(1), 66-109.

Torre, S. (2010). Centered assertion. Philosophical Studies 150(1), 97-114.

von Fintel, K. (2004). Would you believe it? The king of France is back! Presuppositions and truth-value intuitions. In M. Reimer and A. Bezuidenhout (Eds.), Descriptions and Beyond, pp. 315-341. Oxford: Oxford University Press.

Wedgwood, R. (2007). The Nature of Normativity. Oxford University Press.

Yablo, S. (2006). Non-catastrophic presupposition failure. In J. J. Thomson and A. Byrne (Eds.), Content and Modality: Themes From the Philosophy of Robert Stalnaker, pp. 164-180. Oxford University Press. 